América sin Nombre, n.o 21 (2016): 117-128

DOI: 10.14198/AMESN.2016.21.09

ISSN: 1577.3442 / eISSN: 1989-9831

Fecha de recepción: 23/07/2016

Fecha de aceptación: 09/11/2016
Puede citar este artículo como:

Rivera Krakowska, Octavio. "Teatro breve, regalo de Sor Juana a los años de los condes de Galve». Teatro breve virreinal. Miguel Zugasti (coordinador). América sin Nombre, 21 (2016): 117-128, DOI: 10.14198/ AMESN.2016.21.09

Link para este artículo: http://dx.doi.org/10.14198/AMESN.2016.21.09

\title{
Teatro breve, regalo de Sor Juana a los años de los condes de Galve
}

\author{
Short plays, Sor Juana's birthday gift to the Count and the Countess of Galve
}

\author{
Octavio Rivera Krakowska* \\ Universidad Veracruzana
}

\section{Resumen}

De entre la vasta producción para la escena de Sor Juana Inés de la Cruz, las loas cortesanas de su teatro breve han sido las menos estudiadas, a excepción, quizá, de la loa a la comedia Los empeños de una casa y la atribuida a Amor es más laberinto. En el presente trabajo se revisan dos de estas loas, las compuestas para los cumpleańos del virrey conde de Galve y de su esposa Elvira de Toledo. Me permito integrar información sobre las loas que se encuentra dispersa en varios textos, hacer algunas observaciones sobre la edición de estas loas en la Obra completa de Sor Juana a cargo de Alfonso Méndez Plancarte y Alberto G. Salceda, y anotar ciertas particularidades de su representación teatral.

Palabras clave: Teatro novohispano, Sor Juana Inés de la Cruz, loas cortesanas, Condes de Galve.

\begin{abstract}
Among the large dramatic production of Sor Juana Inés de la Cruz, the loas cortesanas of her short plays have been the least studied, except perhaps the loa to comedy Los empeños de una casa and the one attributed to Amor es más laberinto. In this paper, the intention is to review two of these loas, written for the birthdays of viceroy Earl of Galve and his wife Elvira de Toledo. I allow myself to integrate information about the loas that is dispersed in various texts, make some observations on the edition of these loas in the Complete Works of Sor Juana by Alfonso Méndez Plancarte and Alberto G. Salceda and review some features of their theatrical representation.
\end{abstract}

Keywords: Theatre of New Spain, Sor Juana Inés de la Cruz, loas cortesanas, Earls of Galve.

De entre la vasta producción para la escena de Sor Juana Inés de la Cruz, las loas cortesanas de su teatro breve han sido las menos estudiadas, a excepción, quizá, de la loa a la comedia Los empeños de una casa y la atribuida a Amor es más laberinto. La intención del presente trabajo es revisar dos de estas loas, las compuestas para los cumpleaños del virrey conde de Galve y de su esposa Elvira de Toledo. Me permito integrar información sobre las loas que se encuentra dispersa en varios textos, hacer algunas observaciones

\footnotetext{
* Doctor en Literatura Hispánica por El Colegio de México. Es Miembro del Sistema Nacional de Investigadores (SNI) en México. Actualmente es Profesor de Tiempo Completo de la Facultad de Teatro de la Universidad Veracruzana y Coordinador del Posgrado en Artes Escénicas de la misma universidad. Su trabajo docente y de investigación está enfocado, particularmente, en la dramaturgia y el teatro novohispanos, y mexicano de la primera mitad del siglo xx.
} 
sobre la edición de estas loas en la Obra completa de Sor Juana a cargo de Alfonso Méndez Plancarte y Alberto G. Salceda, y anotar algunas particularidades y aspectos de su representación teatral.

\section{Uno}

Los condes de Galve, virreyes de Nueva España, Gaspar de la Cerda Sandoval Silva y Mendoza ${ }^{1}$, y Elvira de Toledo, su esposa, arribaron a Veracruz, Nueva España, el 18 de septiembre de 1688. La entrada del virrey a la ciudad de México, dispuesta y engalanada para su recepción, se realizó el 4 de diciembre de aquel año (Gutiérrez Lorenzo 64; Rubio Mañé 156-157).

El trigésimo virrey de Nueva España, Gaspar de la Cerda Sandoval Silva y Mendoza, VIII conde de Galve-hijo de Rodrigo de Silva, IV duque de Pastrana y príncipe de Melito y de Catalina de Sandoval y Mendoza, VIII duquesa del Infantado-, nació en el palacio de los duques de Pastrana el sábado 11 de enero de 1653 y recibió los nombres de Gaspar, Melchor, Baltasar María y José, Agustín, Francisco Joaquín y Pablo (Gutiérrez Lorenzo 35-38).

En 1677, el conde de Galve contrajo matrimonio con doña María Atocha Ponce de León y Guzmán, con quien tuvo dos hijos: José Manuel Antonio de Silva y Guzmán y Josefa María, ambos murieron a los pocos meses de haber nacido. Doña María Atocha murió en 1684 a consecuencia del nacimiento de su hija Josefa (Gutiérrez Lorenzo 40-41; Rubio Mañé 260).

El conde de Galve se casó por segunda vez entre 1684 y 1688, año, este último, en que viaja a México con su nueva esposa. En esta ocasión la boda fue con Elvira María de Toledo, hija de don Fadrique de Toledo y Osorio, VII marqués de Villafranca y II de Villanueva de Valenzuela, IV duque de Fernandina y príncipe de Montalván, virrey de Sicilia y Capitán General del Mar, y de doña Manuela de Córdoba, hija de don Antonio Fernández de Córdoba, VII duque de Sesa. Don Gaspar y doña Elvira no tuvieron descendencia (Gutiérrez Lorenzo 41; Description... 182; Rubio Mañé 260).

1. Sobre la familia y las variantes en el orden del nombre y los apellidos de Gaspar de la Cerda, VIII conde de Galve, véase Gutiérrez Lorenzo, 32-35.

\section{Dos}

Como sabemos, Sor Juana escribió obras dramáticas y/o poemas para varios de los virreyes y virreinas de Nueva España, de ahí que la literatura dedicada a los condes de Galve no sea una excepción, ni tampoco la exaltación de sus personas que en su obra están colmados de virtudes, valentía y belleza. Una vez más, como antes había ocurrido con los virreyes marqueses de Mancera y los de la Laguna, Sor Juana cumplía con los condes de Galve los deberes para con la autoridad civil, quizá, además, ya obligada por su fama como ingenio novohispano y, por qué no, quizá por el afecto que nacía de la amistad (véase Sabat de Rivers 1998).

Para los virreyes condes de Galve, Sor Juana escribió, entre 1688 y 1691, para él, la Loa a los años del excelentísimo señor Conde de Galve (OC, IV, 185207), un Laberinto endecasílabo para dar los años la excelentísima señora Condesa de Galve, al excelentisimo señor Conde, su esposo (OC, I, 176-177), y una silva (OC, I, 331-335); y, para ella, unas seguidillas (OC, I, 208-209), cinco romances (OC, I, 117-128), entre ellos uno "en ocasión de cumplir años» $(O C$, I, 120-123); y un Encomiástico poema a los años de la excelentísima señora Condesa de Galve (OC, III, 462-482).

Dentro del conjunto de textos para los condes de Galve, como vemos, se encuentran cuatro composiciones dedicadas al festejo de «dar los años»; dos para él: una loa y un laberinto endecasílabo (que delicadamente es un regalo para que la condesa, a su vez, lo obsequie a su esposo); y dos para ella: un romance y un "poema escénico». En relación con el grupo de poemas a los condes de Galve, Paz opina que de todos estos poemas "la pieza más interesante es el Encomiástico poema a la condesa de Galve» (352).

\section{Tres}

La palabra «cumpleaños» aparece por primera vez, en un diccionario de lengua española, en el de la Real Academia Española de 1780 y se le define así: «El día en que alguno cumple cada uno de los ańos de su edad. Dies aniversaria» (RAE, 1780, 300, 2). Antes, en 1770 , aparece la palabra «años», que es «el día en que alguno cumple ańos, y así se dice: celebrar los años, dar los años. Natalitia» (RAE, 1770, 264, 1). Así pues, y como vemos en los títulos de las obras de Sor Juana dedicadas a los virreyes con motivo de cumplir ańos, el uso era que la persona celebrara sus 
«años» y que quien la felicitara en ese día le «diera los años».

Dar los ańos, celebrar los ańos, festejar el cumpleaños propio o el de otra persona, hacer del día en que una persona ha nacido una fecha especial del calendario personal, y afectivo, anual es, en general, costumbre de todos los pueblos. En este día se puede señalar el fin de un ciclo y el principio de uno nuevo para la vida de la persona, y puede ser una celebración del privilegio de vivir. Si hoy hay mayores posibilidades de vivir más años y con mejor calidad de vida, sabemos que esto no era así en el siglo XVII, ni siquiera para los individuos que disfrutaban de poder económico que les permitiera disponer de recursos para una mayor esperanza de vida, época en que el promedio de vida fluctuaba entre los $30 \mathrm{y}$ los 40 años. El conde de Galve, en este caso, murió en España, el 18 de marzo de 1697, a los 44 años de edad, dejando viuda a Elvira (Gutiérrez Lorenzo 44). Celebrar los años podía ser entonces, como ahora, motivo de enorme alegría, especialmente para quien los cumplía y para las personas queridas de su entorno. Si en los textos de Sor Juana dedicados a dar los años la alabanza puede parecer excesiva, habría que tener en cuenta, además, que para el mundo de Sor Juana y para la mentalidad católica de su tiempo y espacio, la vida y los años que una persona viviera eran una dádiva divina, en un universo en donde es Dios quien los concede. Celebrarlos era, pues, una manera de agradecer a Dios la ventura de vivirlos.

\section{Cuatro}

En el Diario de sucesos notables de Antonio de Robles podemos encontrar algunos datos de interés en relación con los cumpleaños de los condes de Galve durante su estancia como virreyes de Nueva España entre 1688 y 1696. Robles menciona los «años» del virrey en 1689, 1690, 1691 y 1695 . Solo en el año de 1689 se consigna que para esta ocasión hubo "comedia en palacio» (II, 174); para 1690 se habla de que «hubo sarao» (II, 195); en 1691 para su homenaje se «arbolaron las banderas para China por los años del virrey, con grandeza» (II, 217); y en 1695 señala: "Años del virrey.- Martes 11, fueron los años del virrey; hubo sobre tarde carreras de los condes y alcaldes, caballeros y criados del virrey, uno de los cuales se quebró una pierna; hubo mucho concurso y palenque y tablados en la plazuela» (III, 10).

Si tenemos en cuenta los graves disturbios populares que tuvieron lugar en la capital de Nueva
España el 8 de junio de 1692 que fueron consecuencia de difíciles condiciones administrativas y conflictos económicos y políticos que venían arrastrándose de tiempo atrás tanto en la península como en el virreinato de Nueva Espańa, puede no resultar extraño que en 1692, aun cuando el cumpleaños de virrey hubiera sido en enero, no se mencione actividad alguna con motivo de su cumpleaños. El motín, que acabó por desequilibrar el gobierno de Galve, lo llevó a la decisión de dejar el cargo y regresar a España, licencia que ya solicitaba desde enero de 1693, misma que le fue concedida en junio de 1695 (Gutiérrez Lorenzo 120-121). ¿Auguraba el virrey su próxima partida para que en su cumpleaños de 1695 se hicieran fiestas caballerescas, "palenque y tablados en la plazuela»? Las fiestas privadas en palacio virreinal con motivo de su cumpleaños en donde había habido "comedia" y "sarao" se modificaban en 1695 , de tal forma que se celebraron de manera abierta y pública muy posiblemente en la Plazuela del Marqués, espacio urbano de la ciudad de México que llegó a emplearse para celebraciones populares ya desde el siglo Xvi. Quizá el boato de las fiestas de 1695 fue una especie de despedida del virrey Galve.

En cuanto al cumpleaños de la virreina, el 20 de octubre -dato que se toma de Robles-, se menciona en 1689, 1691, 1692, 1694 y 1695, y solo actividad festiva en 1689: "Años de la virreina.- Jueves 20, fueron los años de la virreina; hubo comedia en Palacio» (II, 190). En los casos de 1690 y 1693 se suscitaron acontecimientos de la vida pública que para el diario de Robles demandaron mucha mayor importancia que los ańos de la virreina. Habrá que considerar, también, que es posible que Robles no consignara puntualmente las actividades con motivo de los cumpleaños de los virreyes.

\section{Cinco}

Alberto G. Salceda, en el cuarto volumen de la edición de la obras completas de Sor Juana Inés de la Cruz, apunta que en la edición príncipe de 1692 de la loa al virrey se dice: "Loa a los años del excelentísimo señor Conde de Galve, que parece que precedió a la comedia que se sigue» $(O C, \mathrm{IV}, \mathrm{xxi})$, la comedia a que se alude es Amor es más laberinto ${ }^{2}$. El dato,

2. «Loa a los años del Exmo. señor Conde de Galve», Segundo volumen de las obras de Soror Juana Inés de la Cruz. Sevilla: Tomás López de Haro, 1692: 378-388. 
no obstante, se modifica en la edición de la loa en 1693 que señala «Loa que precedió a la comedia que sigue» $(O C, \mathrm{IV}, \mathrm{xxi})$. Después de algunas observaciones sobre el asunto, y cuidadoso de la información, Salceda concluye: «Podemos fechar, pues, la loa con certeza, y la comedia con suma probabilidad, el 11 de enero de 1689 [fecha que da Robles de representación de comedia a los años del virrey] en el Palacio Virreinal de Méjico [sic]»(OC, IV, xxii). Algunos estudiosos han considerado, sin discusión, que la loa encabezó el espectáculo de Amor es más laberinto, comedia de Sor Juana y Juan de Guevara ${ }^{3}$, y que, por lo tanto, Amor es más laberinto también se representó el 11 de enero de 1689. Con base en estos datos se han desarrollado estudios que analizan la loa y la comedia y las relaciones entre ambas obras (Luciani; Rodríguez Garrido). La duda, sin embargo, persiste, y ha sido señalada por varios investigadores, entre ellos por Schmidhuber $(1996,49)$, y posteriormente en el minucioso trabajo de Hernández Araico (2005), así como en otro reciente de Zugasti (2014, 120-122).

Con los escasos datos a la vista, y la información que de la loa se puede desprender en cuanto a fechas de representación de la loa y la comedia de Sor Juana, y de la relación entre ambas, solo es posible suponer que, si es que llegaron a representarse, la loa llegó a la escena el 11, o quizá el 23, de enero de 1689, y posiblemente Amor es más laberinto, el 11 de enero de 1689, ambas en el palacio virreinal. En cuanto a la mención de representación de dos loas el 23 de enero, una para el conde de Galve y otra para el conde de la Monclova, Robles no habla de comedia en ese día (II, 174). Quizá si la loa a los años del virrey compuesta por Sor Juana se representó el 23 de enero podrían haberse omitido, o modificado, los versos que en la loa aluden a la comedia que se representara a continuación, en caso de que aquel 23 de enero no hubiera habido comedia. Claro, en el mundo de lo posible, la misma loa pudo haber sido representada en ambas fechas.

En cuanto al Encomiástico poema, la única fecha de representación de una comedia el día de los años de la virreina, según vimos, es el 20 de octubre de 1689; sin embargo, no hay certeza de que el poema compuesto por Sor Juana se haya escenificado en aquel año.

3. Las ediciones señalan que Juan de Guevara escribió la segunda jornada de la comedia. Schimdhuber (1996, 169-196; 2003, 101-111) plantea que Sor Juana intervino también significativamente en la composición de esa segunda jornada.
Con esta información, que podría no ser tan relevante, nos acercamos una vez más a las enormes lagunas que pueblan el teatro del virreinato de Nueva España. De hecho -quizá a excepción de algunas pocas loas- no hay constancia, no hay testigo de que las composiciones dramáticas de Sor Juana hayan llegado a escena. Las posibles fechas de representación de algunas de sus piezas dramáticas son producto, valioso por supuesto, de conjeturas.

En lo que hace a la loa y el poema escénico que Sor Juana compone para los años de los condes de Galve solo es posible suponer que ambas se representaron en palacio virreinal, durante el primer año de estancia de los condes en el virreinato y sus primeros respectivos cumpleaños en el nuevo mundo en 1689.

\section{Seis}

Las loas, en el mundo de Sor Juana, se componen, normalmente, para ser representadas antes de las comedias, antes de los autos sacramentales y, muy posiblemente, también, más de una, se elaboró para llegar a la escena como una representación teatral independiente que no precedía a ninguna otra, cumpliendo con su propósito principal: la alabanza, el halago, el regalo, la «loa» al sujeto a quien se dedica la fiesta, o a la ocasión, durante la cual se representa.

La loa y el poema escénico que Sor Juana dedica al conde y a la condesa de Galve forman parte del conjunto de las obras dramáticas de la monja que se han denominado modernamente con los nombres de loas «cortesanas», "palaciegas», "palatinas», "profanas» y "humanas», entre otros. Este grupo de obras no incluye las loas que preceden a los autos sacramentales, ni, como se presentan en la edición de sus Obras completas, a las comedias de Sor Juana. Méndez Plancarte las incluye en una sección del tomo III de las Obras completas de Sor Juana a la que titula: "Otras loas», en donde, en su gran mayoría, a excepción de la Loa de la Concepción, son obras compuestas para representarse con motivo de festividades no religiosas.

Quizá el primer estudio general de esta parte de su producción para la escena sea precisamente el que les dedica Méndez Plancarte en su imprescindible edición de la obra completa de Sor Juana (1951-1957), cuyo tomo IV, publicado en 1957, fue preparado por Alberto G. Salceda. Entre otros estudios, en general, sobre algunas características de este conjunto de piezas teatrales están los de Paz (1982), Bravo Arriaga (1995) y Rivera (1999). La atención individualizada 
a loas de este grupo parece ser mucho menor. Entre algunos de los trabajos localizados están el que se detiene en la Loa a los felices años del señor virrey Marqués de la Laguna de Susana Hernández Araico (1992), el que dedica Octavio Castro López a la Loa a los años de la reina nuestra señora, Doña María Luisa de Borbón (1998) y el de Sara Poot-Herrera a la Loa en las huertas $(2007)^{4}$.

De los dos textos breves para la escena que ahora reviso, la que se refiere con más frecuencia es la loa a los años del conde de Galve, no incluida en las obras completas en "otras loas» por considerarla la loa de Amor es más laberinto 5 . Una de las cuestiones de los trabajos ronda precisamente sobre la posibilidad, o no, de que esta loa haya sido compuesta como preámbulo a Amor es más laberinto. Una de las varias preguntas sobre esta relación surge con base en uno de los parlamentos de La Edad, quien comunica a las estaciones del año que "cuidado más soberano / ha dispuesto la Comedia, / la cual siendo de su agrado / y soberana elección, / los festines de Palacio / no la podrán exceder» $(O C, \mathrm{IV}, 194)$.

Si por una parte estos versos responden a la inquietud de los interlocutores sobre el buen resultado del fasto teatral aparentemente organizado en breve tiempo, por otra, llama la atención que, como lo indica Salceda, Sor Juana pueda estar alabando su propia obra (Amor es más laberinto). Afirmación sobre el valor de la comedia que seguirá a la loa, no porque quizá Sor Juana la haya escrito, sino porque "cuidado más soberano» (¿el virrey?) la ha elegido para ser representada. Haya sido, o no, Amor es más laberinto la comedia representada en palacio virreinal el 11 de enero de 1689, La Edad aplaude la elección "soberana» para el homenajeado en el día de su cumpleańos: ¿acaso no se espera dar una enorme

4. En la dramaturgia mexicana, particularmente en la del siglo $\mathrm{xx}$, se encuentran un buen número de obras dramáticas en donde Sor Juana es el personaje protagónico. De entre ellas, las que incluyen algún fragmento de una loa de sor Juana lo hacen de la Loa en las huertas como parte de la acción de las piezas. Así, la encontramos en: Margarita Urueta, Confesiones de Sor Juana Inés de la Cruz (1969); en las dos versiones de la obra de Carlos Elizondo, La décima musa. Homenaje en doce cuadros a Sor Juana Inés de la Cruz (1979) y El sueño y la agonía. Obra dramática en siete cuadros, basada en la vida de Sor Juana Inés de la Cruz (1995) y en Engaño colorido con títeres (1997) de Emilio Carballido. Véase Rivera Krakowska 2012.

5. Entre otros: Salceda, Paz, Revueltas (1995 y 2003), Hernández Araico (1996 y 2005), Palacios Sánchez, Rodríguez Garrido, Poot Herrera (2002) y Luciani. ocasión de contento a quien celebra su cumpleaños? Conviene añadir en relación con la elección de la comedia, si es que fue del conde de Galve, que el virrey gustaba particularmente del teatro y que participaba en la organización de las representaciones teatrales durante su estancia en la corte madrileña (Gutiérrez Lorenzo 40; Paz 351).

Del conjunto de las loas de Sor Juana, y considero aquí también la de Los empeños de una casa, las de los tres autos sacramentales y la atribuida a Amor es más laberinto, las loas a los condes de Galve son dos de las tres más extensas en cuanto a número de versos y se encuentran, si tomamos en cuenta su posible fecha de representación, entre las últimas que compuso Sor Juana.

Méndez Plancarte en su edición de los autos y loas de Sor Juana indica: «Sólo hemos añadido, en estas Obras Teatrales, la división de Escenas (en cada pieza), y la de Cuadros (dentro de los Autos)» (OC, III, xi). A continuación en mis comentarios a las loas para los condes de Galve tomaré en cuenta la división en escenas que propone Méndez Plancarte y que hace también Salceda, cuya edición sigo.

La lista de interlocutores en loa a los años del virrey incluye a los siguientes cinco: La Edad, El Invierno, El Estío, El Otoño, El Verano y a «dos coros de música» $(O C, \mathrm{IV}, 185)$. En la obra hay que considerar que, de acuerdo con los usos de la época, El Estío corresponde, en la noción actual, al verano y, El Verano, a la primavera. No es claro si hay un interlocutor que sea la Música, no se menciona en la lista de interlocutores. En la loa se indica "Música» cuando empieza la obra, voz que emite las coplas de los 18 primeros versos. ¿ $\mathrm{Al}$ indicar «Música» se trata de un interlocutor o de la participación del conjunto coral? En la lista de interlocutores, como vemos, se mencionan "dos coros de música», y en la loa solo se menciona directamente la participación de los coros para los versos 35 a 38 (OC, IV, 186-187), participación posible, por supuesto, pero demasiado breve, mientras que "Música» se mencionará varias veces en el transcurso de la obra. A partir de la escena III -que, aproximadamente, da inicio a la segunda mitad de la loa en el verso 296-, el texto incluye parlamentos en boca de «Música», voz y, quizá presencia de un actor o actriz que la representa.

La edición de Salceda hace varias modificaciones $y$ ajustes en el texto ${ }^{6}$; entre otras, en lo que concierne

6. «Coro 1» $\mathrm{y}$ "Coro 2» son modificaciones de Salceda. Véanse sus notas en $O C, \mathrm{IV}, 570-578$. 
a la participación de "Música», particularmente a partir de la escena III e indica: "Añadimos: Música, antes de cada uno de estos versos [305, 319, 333, $347,361]$ por considerar que así se restaura la forma acostumbrada de estas Loas» $(O C, \mathrm{IV}, 576)$ y más adelante añade:

Creemos que la distribución de los versos entre los personajes, en esta escena, está gravemente alterada en los Textos; por lo que procuramos restaurarla poniéndola en forma más lógica. En dichos Textos, se atribuyen a la Música los vv. 428-432; a la Edad, los 433-435; al Invierno, los 437-440 y a la Música, los 441-448 (OC, IV, 577).

Sin duda las modificaciones de Salceda otorgan un importante peso a la participación de "Música» en la segunda mitad de la loa. Si consideramos, por una parte, como, entre otros, lo hace y señala Hernández Araico (2005), la enorme importancia de la música en este tipo de representaciones en la corte $y$, por otra, que a partir la escena III se inicia propiamente, dentro del mundo de la loa, el festejo al conde de Galve, es posible que la segunda mitad de la loa estuviera concebida para ser representada mediante una conjunción, entre otros elementos escénicos, de palabra, música y canto, y en donde, quizá hubiera, algunas veces, secciones solistas cantadas a cargo de la «Música» y otras por los coros y/o la Música acompañada por los coros. En todo caso, no hay duda de que Sor Juana incluye música y que la hubo en la representación. Es posible que el conjunto musical estuviera formado por instrumentos de cuerda si tomamos en cuenta los versos que dice Estío: «¿Pues a qué fin has juntado / los instrumentos acordes, / si eran más proporcionados / las cajas y los clarines?» (OC, IV, 190-191). La música de esta loa, lamentablemente, como muchos elementos de nuestras artes escénicas, no ha sido localizada.

Como arriba se dijo, la loa a los ańos del conde de Galve es dividida por Méndez Plancarte / Salceda en cinco escenas. La división es útil para observar las secuencias de la acción escénica que en este género de pieza dramática no necesariamente se desarrolla a partir de un conflicto.

La obra empieza, aparentemente con el escenario vacío, quizá con una cortina al fondo, se escucha música y canto (recursos con los que se inician varias de las loas palatinas de Sor Juana en las que se dice: "cantan dentro", "córrese una cortina»), es la «Música» que llama a las estaciones del año. El primer interlocutor que aparece en escena es la
Edad con los atributos de una reina, la acotación indica: «en un trono, la Edad: sentada, muy bizarra, con corona» $(O C, \mathrm{IV}, 185)$. No hay más instrucciones de decorado que un trono que posiblemente esté detrás de una cortina, la cual, no se menciona, solo se indica "Descúbrese la Edad» (OC, IV, 186). En acto de tal naturaleza lo adecuado es que sea una reina la figura que convoca, organiza y dirige una de las fiestas que se le ofrecen al virrey en su cumpleaños. Acompañada de Música, Edad hace llamar y, a su vez, llama e invita a las partes en que se divide el año. Entran a escena las cuatro estaciones, quizá al mismo tiempo: «Salen el Invierno, el Estío, el Otoño y el Verano» (OC, IV, 187) y se presentan. Es posible que cada uno de estos interlocutores lleve algún objeto que lo identifique visualmente. En su entrada a escena dice el Verano: "Con flores en Enero llega el Verano» $(O C, I V, 187)$, y cuando el Otoño se presenta comunica que: «Cargado de sus frutos viene el Otoño» $(O C, \mathrm{IV}, 187)$, idea que repite versos más adelante $(O C, \mathrm{IV}, 188)$. Las estaciones, en señal de respeto, se inclinan ante la Edad: «Y a tus pies todos postrados, / esperamos ver el fin / para que nos has juntado" (OC, IV, 188).

La Edad explica que desea celebrar al dios Jano y al año que con él da inicio. Las estaciones se extrañan, pues han venido con la intención de celebrar al conde y ahora entienden que van a celebrar a Jano, festejo en el que no desean participar. Edad les comunica que le harán un homenaje a Jano pues hay coincidencias entre él y el conde: el Jano que celebran es Silva, el conde de Galve, que nació en enero y a quien se celebra a través de la metáfora de Jano. Todos de acuerdo, se preguntan cómo pueden preparar algo en tiempo tan corto (como vimos el virrey hizo su entrada a la ciudad en diciembre de 1688), y que, además, no han traído algo para ofrecerle. La Edad los tranquiliza pues todo está ya arreglado: «soberana elección» eligió la comedia y el amor es el mejor regalo; además, si las estaciones son tiempo, qué mejor regalo que darse ellos mismos: «dar años». Invierno le pide que sea Edad quien empiece el festejo.

La celebración comienza, en la escena III, con las palabras de la Edad. A partir de este momento los interlocutores se dirigen al conde, la escena se abre, entonces, a la relación directa de interlocutores con el homenajeado y con el resto de la concurrencia. El espacio físico elimina la división entre actores y espectadores y refuerza la convención de ser, en ese momento, un espacio único, fantástico y festivo: el espacio mágico del convivio de la fiesta teatral. Las 
estaciones se inclinan ante el virrey, le ofrecen, oral y/o físicamente, los objetos que los representan: flores, frutos, sazón y hielo, y explican la alegoría de los objetos. Invierno, cuya participación se destaca de entre las estaciones, quizá porque enero es parte del invierno, aprovecha para hacer alguna broma: «Yo el Invierno soy, postrado / a los pies de vuexcelencia; / que de estar en tal presencia, / juzgo de estar más helado» (OC, IV, 197).

La última escena, la $\mathrm{V}$, se puede dividir en dos partes. La primera formada por nuevos elogios al conde y a su esposa Elvira, a quien alaba Verano, que en ese momento, aparentemente confundido, celebra el cumpleaños de ella (OC, IV, 203). En la segunda parte de esta escena los elogios van para al resto de los espectadores: al virrey saliente, Melchor Portocarrero y Lasso de la Vega, y a su esposa Doña Antonia Jiménez de Urrea, "Venus aragonesa», a sus hijos Antonio, Joaquín y Josefa (Rubio Mañé 258; Zugasti 120-122), a las damas de la corte y a las autoridades presentes. El recurso simple de tomarlos en cuenta al nombrarlos no puede dejar de ser efectivo y, al margen de los motivos políticos y cortesías, nombrar desde la escena a todas estas personas en fiesta de tal magnitud puede proveer de contento a quienes son mencionados. La loa termina con todos los interlocutores pidiendo que "iQuiten los dioses / de nuestros años, y / los tuyos doblen!» (OC, IV, 207).

Los asistentes a la representación de la loa, los virreyes y sus invitados, saben perfectamente que el hecho escénico se levanta como un homenaje al virrey en el día de su cumpleaños. No debe parecer desmedida -ni como seńala Bravo Arriaga «necesariamente insincera» (46)- la profusión del halago en la loa. Lo que se espera del acto teatral es quizá el asombro y el placer ante los ricos tejidos de la palabra y de la construcción dramática, el virtuosismo de actores y cantantes, la fantasía desbordada y la suntuosidad de los trajes ${ }^{7}$, la atmósfera sonora musical de un universo, que en el momento de la loa es todo el universo, el real y el imaginado, universo en el cual sus habitantes, seres superiores y sobrenaturales, festejan al virrey (o a la autoridad en cuestión). Festejo al cual, quienes asisten, tienen el privilegio de haber sido invitados y que comparten el espacio físico en donde tiene lugar la representación teatral,

7. Para las instrucciones sobre vestuario, accesorios y utilería que ofrece Sor Juana en las loas cortesanas véase Rivera Krakowska, 2003. muy probablemente el salón de comedias del palacio virreinal, transformado todo, por el arte del teatro, en el centro del universo en donde se lleva a cabo la representación.

\section{Siete}

En los últimos años los estudios sobre la vida y actividades de las virreinas han ido en aumento (Dodge y Hendricks, Calvo y Colombí), aunque todavía es mucho lo que se ignora de estas mujeres. En opinión de Antonio Rubial, «una buena parte de la vida de la corte [...] [virreinal novohispana dependía] de la virreina. [...] La vida cortesana se definió así, en buena medida, a partir de los patrones femeninos. [...] Seguramente fueron las virreinas quienes introdujeron el gusto por la poesía lírica y por los valores del amor cortés» (2005, 122-123).

El caso de Elvira de Toledo, como los de Leonor Carreto y María Luisa Manrique de Lara, ha sido especialmente estudiado por sus relaciones con Sor Juana. Hacia 1993, la eminente sorjuanista Georgina Sabat de Rivers dice: «Sor Juana le dedicó muchas composiciones a Elvira de Toledo, la condesa de Galve (o Galbe), virreina de México, pero no he encontrado, hasta ahora, nada sobre ella» (5). Afortunadamente, poco a poco, la organización y posibilidades de consulta de archivos se enriquecen y mejoran día a día, lo cual en el caso de Elvira de Toledo ha nutrido la información. En el mismo 1993, Dodge y Hendricks publicaron veintisiete cartas de la virreina con familiares y amigos que coinciden con el periodo de la estancia de la condesa en Nueva España. En ese mismo año, Gutiérrez Lorenzo habla de las relaciones comerciales de la condesa con su cuñada, doña María de Haro y Guzmán (67-68). Sobre la virreina, también aportan información Manuel Ramos (40-41) y Antonio Rubial $(2014,39)$.

Posiblemente, como arriba se ha dicho, el cumpleańos de dońa Elvira era el 20 de octubre, fecha que propone Méndez Plancarte como posible para la representación del Encomiástico poema (OC, III, 717). Habría que considerar también que en esa fecha se habla de la representación de una "comedia» y que por lo tanto podría no ser necesariamente la de la representación del Encomiástico poema.

El Encomiástico poema es incluido por Méndez Plancarte dentro del conjunto de las loas de Sor Juana. En adelante, en atención al nombre que recibe en la edición de 1692, me referiré a esta obra como 
«Poema» y no como «loa». Si por su forma, extensión, tipo de personajes y tema, el Poema puede ser considerado una loa, el hecho de llamarlo Poema podría sugerir que el texto no fue escrito precisamente para preceder a la representación de una comedia y que, quizá, fue compuesto para formar parte de las actividades de la fiesta (o las fiestas) por el cumpleaños de la virreina, y que su representación (si es que llegó a efectuarse) pudiera haberse realizado independientemente de otra representación teatral.

Dice Méndez Plancarte: «En las loas palatinas y sus afines [...] prevalece a menudo el interés 'espectacular' -decorativo, coreográfico y musical-, ya rumbo a la opereta y aun al ballet [...] de modo que los bailes y entremeses van ganando terreno en ellas» $(O C$, III, lxiii-lxiv), y en relación específicamente con el Poema, señala:

No tan sólo le da entrada a coros y estribillos cantados, sino que es todo de esencia musical, aun sin llegar a convertirse en opereta o zarzuela. 'La Música' y 'las Notas', sus personajes, basan su habla alegórica en las afinidades de la Armonía con la Belleza y el Tiempo; y sus graciosos alardes eruditos de teoría musical reflejan una de las aficiones comunes de la Autora y de la joven Virreina. / [...] la visualidad decorativa y movimiento espectacular nacen - por modo muy calderoniano- de un conceptuoso juego de 'anagramas', tejidos por las letras o las sílabas iniciales de los personajes, completando el encomio de los Virreyes (OC, III, lxxxviii).

Como antes se ha dicho, Méndez Plancarte dividió en escenas su edición de la obra dramática de Sor Juana (OC, III, xi). En el caso del Poema, la división propone seis escenas, que son:

- Escena I (vv. 1-84). Aparece La Música, se presenta y expone la razón de su presencia: celebrar los años y la belleza de Elvira $(O C$, III, 463-465).

- Escena II (vv. 85-158). Para el festejo la Música «invoca» a las notas musicales. Cada una de las seis entran una a una a escena y se presentan (OC, III, 465-468).

- Escena III (vv. 159-328). Música se detiene en hablar de asuntos musicales, de la belleza y la armonía, subraya que todo lo que es hermoso lo es porque posee las proporciones justas. Música pregunta a cada una de las notas su identidad, al mismo tiempo que de una en una, les entrega unas "tarjas» (tarjetas, carteles) cada una con una de las letras de su nombre.
Las notas, entonces, emplean una parte de la voz con que se designan para componer una palabra que nombra una cualidad de la virreina (OC, III, 468-473).

- Escena IV (vv. 329-444). Música recoge las tarjas de manos de las notas con el propósito de crear una frase distinta con ellas, las mezcla y entrega de nuevo. En una primera vuelta de este juego, las letras (sonidos) construyen la frase "ELVIRA SOLA» y en la segunda, una vez que ha recogido, mezclado y entregado otra vez las tarjas, la frase «EL SILVA AMOR». De esta cuarta escena de elogios y afectos para la virreina y su consorte (OC, III, 473-479), la edición pasa a la:

- Escena VI (vv. 445-540), compuesta por vivas para la virreina y su esposo entonadas por Música, Notas y Coro (OC, III, 479-482).

Como vemos, falta la escena V. ¿Méndez Plancarte dividió en cinco escenas? Si fue en seis ¿qué versos componen la escena V? El Poema, en la edición de Méndez Plancarte, no pierde continuidad de la escena IV a la VI, con omisión de la V, ni hay texto perdido en relación con la edición de 1692. Me parece que en este punto se trata solo de una errata en la edición de 1955.

El Poema gira, pues, en torno a festejar a la virreina mediante la exaltación de su «inmensurable» belleza que, paradójicamente, puede caber en el muy reducido número de sus años de vida. Para explicar este extraordinario fenómeno es precisamente que interviene la Música: todo es cuestión de la proporción y la armonía que ella misma, Música, representa con los sonidos musicales.

Desde el mismo arranque del Poema, Sor Juana invita al lector -al espectador- al juego de las sinestesias. Ya en alguna lira hablaba de "oír con los ojos» $(O C, \mathrm{I}, 313)$, ahora en el Poema insiste en la idea: «escuchar con los ojos». Los sonidos musicales (invisibles a los ojos), en el mundo del Poema, remiten al cuerpo de Elvira (belleza plástica que ignora el oído, y aunque es forma humana que no aparece en escena, la música la evoca, construye y representa) y lo son también, en la representación, las formas humanas que adquieren los personajes de Música $y$ las Notas ${ }^{8}$. El espectador, pues, efectivamente,

8. En torno a las ideas sobre teoría y filosofía de la música que Sor Juana vierte en el Poema, véanse los eruditos trabajos de Lavista, Miranda y Tello. 
gracias a la representación teatral «escucha con los ojos». Así, la música es la imagen sonora de Elvira, y Elvira la expresión en cuerpo humano y femenino de la música. Si Sor Juana no compone una pieza musical que permita escuchar la belleza del cuerpo y el rostro de Elvira, sí arma una pequeña pieza dramática que lo intenta y explica en la escena, y que pretendería ser una especie de espejo (creado por imágenes, movimientos, palabras y sonidos musicales) en el que se mira la propia virreina, persona que está físicamente en el centro del salón en donde se representa el Poema.

Si el teatro, entre otros muchos objetivos, como espectáculo, desea seducir a los sentidos, privilegiando a la vista y al oído, qué mejor ocasión, para Sor Juana, que en el cumpleaños de la virreina, la mujer y su belleza, celebre con el Poema -y, por supuesto, con su representación teatral-, en el arrobamiento y la sobrecarga sensorial, el poder de no solo oír sino ver la música, y no solo mirar sino escuchar la forma, el color, la textura, la lozanía del rostro y el cuerpo de Elvira. En el teatro es posible crear esta magia y hacer este regalo visible y audible a un tiempo.

\section{Ocho}

Veamos cómo parecen realizarse algunos aspectos de la «visualidad decorativa», y el «movimiento espectacular» de que habla Méndez Plancarte. El Poema invita a sensibilizar los sentidos apelando a la sinestesia (pues se verán, alegóricamente, las personas de la Música y las Notas musicales y se escuchará a la belleza plástica), y se juega, entre otros elementos, con la "plasticidad visual» de la música con un recurso quizá simple pero efectivo y sorpresivo: el empleo de trece "tarjas» (tarjetas, carteles), cada una de ellas con una de las letras que forman las palabras que designan a las notas musicales: VT, RE, MI, FA SOL, LA? . Como antes he dicho, Música entrega las tarjas a las notas a medida que cada una de ellas se presenta; las Notas, al recibirlas, las muestran. Después de hacerlo, para continuar el juego, e inesperadamente para el público, armar con esas letras el homenaje a Elvira, y de paso a su esposo Gaspar -como antes elogió rápidamente a Elvira en la loa al virrey-, Música recoge las tarjas de manos de

9. Sobre la razón por la cual Sor Juana solo emplea seis notas, véase Lavista 197-198. las notas y, aparentemente, las revuelve para volver a entregarlas, siempre en el orden del VT al LA, a cada una de las notas, acción con la que se forman, una después de la otra dos frases, como hemos visto: primero: ELVIRA SOLA y, en la segunda vuelta: EL SILVA AMOR.

Sobre el teatro, el tablado, la imagen visual se recompone y organiza coreográficamente en varias ocasiones y, en lugar de aparatos y tramoyas, en la escena se juega con la presencia, traje, color, movimiento y número de cuerpos humanos y las tarjas que cambian de dueño y de sentido siempre controladas, en el mundo de la obra, por la armonía de Música quien, por supuesto, canta en varias ocasiones. Sor Juana lo indica, así como que Música reparte las tarjas, las mezcla y las vuelve a entregar. No hay mayores indicaciones escénicas, ni de decorados, ni de vestuario, ni de movimiento, fuera de, como he dicho, la cortina que se descorre al inicio de la obra y el seńalamiento de la entrada a escena de los interlocutores (OC, III, 463-467).

Una pequeña observación sobre la primera vez que se realiza este juego -que de manera similar Sor Juana emplea también en la loa a los ańos de Fray Diego Velázquez de la Cadena, en donde en vez de tarjas son eslabones con las letras de la palabra "cadena» (OC, III, 483-502)-, una vez que se ha formado la frase ELVIRA SOLA, Música dice: «que en el RE, MI, FA, SOL, LA / se contenga ELVIRA SOLA» (OC, III, 476). En el verso que menciona las notas falta la V de ELVIRA, es decir el VT ¿Dónde quedó el VT? ¿Omisión poética para conservar el número de sílabas del verso?

En el curso de la obra la escena se va poblando poco a poco: con la voz fuera del escenario de Música y su entrada, y con la de cada una de las notas, hasta nutrir la escena con la presencia de un coro, quizá fuera del escenario pero llenando de voces, música y algarabía no solo el tablado sino todo el salón de la representación.

A diferencia de otras muchas de las loas cortesanas que escribió Sor Juana para celebrar los años de miembros de la corona española y que, muy posiblemente se representaron en el palacio virreinal, las loas que compuso para los virreyes y para alguna autoridad religiosa en Nueva España se representaron con la presencia de los individuos homenajeados. La exaltación, en las loas cortesanas, de las figuras de Carlos II, su esposa María Luisa de Orleans, la reina madre y otras personas, tendría la ventaja, si así lo podemos decir, de la ausencia del homenajeado: se alaba de manera indirecta sin la presión de la persona 
viva que escucha y mira en la escena el homenaje que se le rinde. A ello habría que añadir que, posiblemente, la autora, así como todos o la mayoría de los miembros de la compañía que representa (actores, músicos, maestro de ceremonia), conocen personalmente, en mayor o menor medida, al sujeto a quien se le dedica el espectáculo. En estas circunstancias el compromiso puede ser mayor pues la respuesta es inmediata. El regalo teatral hha complacido o no al receptor del homenaje?

Parece que no hay noticia de que Sor Juana hubiera tenido la oportunidad de un encuentro personal con el conde de Galve antes de la escritura y representación de la loa; parece imposible, además, que su condición de monja de clausura le hubiera permitido asistir a la representación. Como en el caso de las loas para la realeza, la que dedica al conde se apoya, en lo que concierne a la información que sobre él se vierte en el texto dramático, en algunos muy pocos datos que recibiría para cumplir con la encomienda. Aunque no es una loa con motivo del recibimiento del virrey, casi podría formar parte de las festividades por su arribo. La loa al conde de Galve es la presentación de Sor Juana ante la nueva máxima autoridad civil del virreinato.

Si para el caso del virrey, quizá el tiempo de preparación de la loa fue corto y la información sobre su persona breve, para el Poema a la virreina hubo mayor oportunidad y es posible que Sor Juana hubiera llegado a conocer y tratar personalmente a doña Elvira de Toledo. Quizá haya sido ese conocimiento el que sugirió a Sor Juana componer el Poema sobre la alegoría de la música, arte probablemente apreciado por la condesa y, como sabemos, uno de los placeres de la monja.

La experiencia de Sor Juana al escribir esta loa y este Poema es ya larga, conoce los recursos y la poética del género. Con sus propios saberes poéticos, dramáticos y teatrales, construye piezas dramáticas con riqueza de movimiento poético, polifonía vocal y musical, sugerencias para la fascinación del espectador en la plástica y el movimiento de la escena: todo ideado en un crescendo escénico. Si, efectivamente, como tantas veces se ha dicho, las loas cortesanas de Sor Juana son teatro de circunstancias, ello no disminuye ni su calidad dramática ni teatral, méritos suficientes que parece no han visto los creadores escénicos para hacer con ellas deslumbrantes espectáculos para la escena contemporánea.

\section{Bibliografía}

Bravo Arriaga, María Dolores. «Sor Juana cortesana y Sor Juana monja». Memorias del coloquio internacional Sor Juana Inés de la Cruz y el pensamiento novohispano. Toluca: Instituto Mexiquense de Cultura, 1995: 41-48.

Calvo, Hortensia, y Beatriz Colombi (eds.). Cartas de Lysi. La mecenas de Sor Juana Inés de la Cruz en correspondencia inédita. Madrid-México: IberoamericanaBonilla, 2015.

Carballido, Emilio. Engaño colorido con titeres. Pasaporte con estrellas. Xalapa: Universidad Veracruzana, 1997: 7-50.

Castro López, Octavio. Sor Juana Inés de la Cruz y el último de los Austrias. México: Universidad Nacional Autónoma de México - Universidad Veracruzana, 1998.

Descriptión genealógica y historial de la ilustre casa de Sousa, con todas las reales y muchas de las grandes que de ella participan, continuada desde que faltó la varonía y fue sobstituida por la real de Portugal en los Sousas Dionises. Madrid: Imprenta de Francisco Xavier García, 1770.

Dodge, Meredith D., y Rick Hendricks (eds.). Two Hearts, one Soul. The Correspondence of the Condesa de Galve, 1688-1696. Albuquerque: University of New Mexico Press, 1993.

Elizondo, Carlos. La décima musa. Homenaje en doce cuadros a Sor Juana Inés de la Cruz. México: Imprenta Carma, 1979.

Elizondo, Carlos. El sueño y la agonía. Obra dramática en siete cuadros, basada en la vida de Sor Juana Inés de la Cruz. Toluca: Instituto Mexiquense de Cultura, 1995.

Gutiérrez Lorenzo, María Pilar. De la corte de Castilla al virreinato de México: el conde de Galve (1653-1697). Madrid: Diputación Provincial-Gráficas Dehon, 1993.

Hernández Araico, Susana. "Venus y Adonis en Calderón y Sor Juana: la primera ópera americana, ¿en la Nueva Espańa?» Ysla Campbell (coord.). Relaciones literarias entre España y América en los siglos XVI y XVII. Ciudad Juárez: Universidad Autónoma de Ciudad Juárez, 1992: 137-151.

Hernández Araico, Susana. «Festejos teatrales mitológicos de 1689 en la Nueva Espańa y el Perú, de Sor Juana y Llamosas: una aproximación crítica». José Pascual Buxó (ed.). La cultura literaria en la América virreinal. México: Universidad Nacional Autónoma de México, 1996: 317-326.

Hernández Araico, Susana. "Amor es más laberinto: producción palaciega, ¿zarzuela parchada?» Sandra 
Lorenzano (ed.). Aproximaciones a Sor Juana. México: Universidad del Claustro de Sor Juana-Fondo de Cultura Económica, 2005: 133-149.

JuANA INÉS DE LA CRUZ, Sor. «Encomiástico poema a los años de la excelentísima señora Condesa de Galve». Segundo volumen de las obras de Soror Juana Inés de la Cruz. Sevilla: Tomás López de Haro, 1692: 368-377.

JuANa INÉS DE LA CRUZ, Sor. «Loa a los años del excelentísimo señor Conde de Galve». Segundo volumen de las obras de Soror Juana Inés de la Cruz. Sevilla: Tomás López de Haro, 1692: 378-388.

Juana Inés de la Cruz, Sor. Obras completas. III. Autosy Loas. Alfonso Méndez Plancarte (ed.). México: Fondo de Cultura Económica, 1955. [1 ${ }^{\text {a }}$ reimpr. 1976].

Juana Inés de la Cruz, Sor. Obras completas. IV. Comedias, sainetes y prosa. Alberto G. Salceda (ed.). México: Fondo de Cultura Económica, 1957. [1 ${ }^{\mathrm{a}}$ reimpr. 1976].

Lavista, Mario. «Sor Juana musicus». Memorias del coloquio internacional Sor Juana Inés de la Cruz y el pensamiento novohispano. Toluca: Instituto Mexiquense de Cultura, 1995: 195-201.

LuCiani, Frederick. Literary Self-Fashioning in Sor Juana Inés de la Cruz. Cranbury: Associated University Presses, 2004.

Miranda, Ricardo. «Sor Juana y la música: una lectura más». Memorias del coloquio internacional Sor Juana Inés de la Cruz y el pensamiento novohispano. Toluca: Instituto Mexiquense de Cultura, 1995: 253-270.

Palacios Sánchez, Refugio Amada. Hacia una lectura contemporánea de 'Amor es más laberinto'. Xalapa: Universidad Veracruzana, 1997.

Paz, Octavio. Sor Juana Inés de la Cruz o las trampas de la fe. México: Fondo de Cultura Económica, 1982 [2a. edición 1983].

Роot Herrera, Sara. «Cien años de teatralidad». Raquel Chang-Rodríguez (coord.). Historia de la literatura mexicana. 2. La cultura letrada en la Nueva España del siglo XVII. México: Siglo XXI-Universidad Nacional Autónoma de México, 2002: 195-243.

Poot-Herrera, Sara. «La virreina se divierte. Loa en las huertas de Sor Juana a la Condesa de Paredes». Judith Farré Vidal (ed.). Teatro y poder en la época de Carlos II. Fiestas en torno a reyes y virreyes. Madrid: Iberoamericana, 2007: 237-255.

Ramos, Manuel. «Los virreyes de la casa de los Austrias». El otro yo del rey: virreyes de la Nueva España, 15311821. México: Instituto Nacional de Antropología e Historia-Miguel Ángel Porrúa, 1996.

Real Academia Española. Diccionario de la lengua castellana. Tomo cuarto, que contiene las letras
G.H.I.J.K.L.M.N. Madrid: Imprenta de la Real Academia Española, 1734.

Real Academia Española. Diccionario de la lengua castellana compuesto por la Real Academia Española. Segunda impresión corregida y aumentada. Tomo primero. A-B. Madrid: Ibarra, 1770.

Real Academia Española. Diccionario de la lengua castellana compuesto por la Real Academia Española, reducido a un tomo para su más fácil uso. Madrid: Ibarra, 1780.

Revueltas, Eugenia. "Amor es más laberinto». Margarita Peña (comp.). Cuadernos de Sor Juana. Sor Juana Inés de la Cruzy el siglo XVII. México: Universidad Nacional Autónoma de México, 1995: 231-242.

Revueltas, Eugenia. «Estrategias emblemáticas en el teatro». Aurelio González, Serafín González, Alma Mejía, María Teresa Miaja de la Peńa y Lillian von der Walde Moheno (eds.). Estudios del teatro áureo. Texto, espacio y representación. México: Universidad Autónoma Metropolitana-El Colegio de México-AITENSO, 2003: 139-155.

Rivera Krakowska, Octavio. «Espacio escénico, iluminación y vestuario en Amor es más laberinto». Memoria del III Encuentro de Investigación Teatral. México: CITRU-INBA, 1992: 83-99.

Rivera Krakowska, Octavio. "Algunos recursos de la puesta en escena en la obra dramática de Sor Juana Inés de la Cruz, México 1670-1690». Investigación Teatral, 3 (2003): 37-53.

Rivera Krakowska, Octavio, «Sor Juana Inés de la Cruz como personaje en la dramaturgia mexicana (18762000)». Tema y Variaciones de Literatura. Mujeres en la dramaturgia mexicana, 39.2 (2012): 81-111.

Robles, Antonio de. Diario de sucesos notables (16651703). 3 vols. Antonio Castro Leal (ed.). México: Porrúa, 1972, 2a ed.

Rodríguez Garrido, José Antonio. «Escritura femenina y representación del poder en Amor es más laberinto de Sor Juana Inés de la Cruz (Loa y comedia)». Enrique Ballón Aguirre y Óscar Rivera Rodas (eds.). De palabras, imágenes y simbolos: homenaje a José Pascual Buxó. México: Universidad Nacional Autónoma de México, 2002: 615-634.

Rubial García, Antonio. Monjas, cortesanos y plebeyos. La vida cotidiana en la época de Sor Juana. México: Taurus, 2005.

Rubial García, Antonio. "Las virreinas novohispanas. Presencias y ausencias». Estudios de Historia Novohispana, 50 (2014): 3-44.

Rubio Mañé, José Ignacio. El virreinato I. Orígenes y jurisdicciones, y dinámica social de los virreyes. México: Fondo de Cultura Económica-Universidad Nacional 
Autónoma de México, 2005, 2a reimpresión. [1 ${ }^{a}$ ed. Universidad Nacional Autónoma de México, 1955; $2^{a}$ ed. Universidad Nacional Autónoma de MéxicoFondo de Cultura Económica, 1983].

Sabat DE Rivers, Georgina. «Mujeres nobles del entorno de Sor Juana». Sara Poot Herrera (ed.). Y diversa de mi misma entre vuestras plumas ando. Homenaje internacional a Sor Juana Inés de la Cruz. México: El Colegio de México, 1993. [1ª reimpr. 1997, pp. 1-19. También en Georgina Sabat de Rivers. En busca de Sor Juana. México: Universidad Nacional Autónoma de México, 1998: 97-130].

SALCEDA, Alberto G. «Introducción». Sor Juana Inés de la Cruz, Obras completas. IV. Comedias, sainetes y prosa. México: Fondo de Cultura Económica, 1957. [1ª. reimpr. 1976].

Schmidhuber de la Mora, Guillermo. Sor Juana, dramaturga. Sus comedias de "falda y empeño». Puebla:
Benemérita Universidad Autónoma de PueblaCONACULTA, 1996.

Schmidhuber de la Mora, Guillermo. Cátedra de damas. Sor Juana y Elena Garro. Ensayos. Guadalajara: Universidad de Guadalajara, 2003.

Tello, Aurelio. «Sor Juana, la música y sus músicos». Memorias del coloquio internacional Sor Juana Inés de la Cruz y el pensamiento novohispano. Toluca: Instituto Mexiquense de Cultura, 1995: 465-482.

Urueta, Margarita. Confesiones de Sor Juana Inés de la Cruz. Antonio Magaña-Esquivel (comp.). Teatro Mexicano, 1969. México: Aguilar, 1972: 99-160.

Zugasti, Miguel. «Teatro y fiesta en honor del nuevo virrey: dos loas al Conde de la Monclova en Puebla de los Ángeles (1686) y Lima (1689)». Miguel Zugasti, Ester Abreu y M. Mirtis Caser (eds.). El teatro barroco: textos y contextos. Vitória: Universidade Federal do Espírito Santo-AITENSO, 2014: 115-167. 